\title{
Porencephaly-microcephaly-bilateral congenital cataract syndrome
}

INSERM

\section{Source}

INSERM. (1999). Orphanet: an online rare disease and orphan drug data base.

Porencephaly-microcephaly-bilateral congenital cataract syndrome. ORPHA:306547

Porencephaly-microcephaly-bilateral congenital cataract syndrome is a rare, genetic, central nervous system malformation syndrome characterized by bilateral congenital cataracts and severe hemorrhagic destruction of the brain parenchyma with associated massive cystic degeneration, enlarged ventricles and subependymal calcification. Patients typically present generalized spasticity, increased deep tendon reflexes and seizures. Hepatomegaly and renal anomalies have also been reported. 